\title{
Toprağa uygulanan tütün ve badem atıklarından elde edilen biyokömürlerin elementel analizleri ve SEM özelliklerinin
} karşılaştırılması

\section{Elementary analyses and comparison of SEM characteristics of biochars obtained from tobacco and almond residues applied to soil}

\author{
Ahmet ÇELIK ${ }^{1 *}$, Memet inAN ${ }^{1}$ iD, Erdal SAKIN² \\ ${ }^{1}$ Adıyaman Üniversitesi Tarım Bilimleri ve Teknolojileri Fakültesi 02400 Kahta/Adıyaman \\ ${ }^{2}$ Harran Üniversitesi Ziraat Fakültesi Toprak Bilimi ve Bitki Besleme Bölümü, Şanlıurfa
}

\section{To cite this article:}

Çelik, A., İnan, M. \& Sakin, E. (2019). Toprağa uygulanan elde edilen biyokömürlerin elementel analizleri ve SEM özelliklerinin karşılaştırılması. Harran Tarım ve Gıda Bilimleri Dergisi, 23(4):500510.

DOI: $10.29050 /$ harranziraat.565323

Address for Correspondence: Ahmet ÇELIK

e-mail:

ahmetcelik@adiyaman.edu.tr tütün ve badem atıklarından

Öz

Tarımda sürdürülebilirlik kavramının önemsendiği bir süreçte yenilenebilir enerji kaynağı olarak kullanılan biyokütlenin dönüşümü ve atık yönetimi gibi konular ilgi çekmeye başlamıştır. $\mathrm{Bu}$ nedenle çalışmada, toprağa uygulanan tütün ve badem atıklarından elde edilen biyokömürün elementel özellikleri ve mikro morfolojik açıdan topraklar üzerine etkileri araştırılmıştır. Çalışma, tarla koşullarında, üç tekerrürlü olarak, her blokta 5 parsel oluşturulmuş olup, bu parsellerden ikisine tütün, ikisine badem biyokömürü, bir tanesine kimyasal gübre uygulaması yapılarak anason bitkisi (Pimpinella anisum L.) yetiştirilmiştir. Denemede parsellerde kullanılan biyokömürlerin (tütün ve badem) elementel, toplam karbon (TC), inorganik karbon (IC), toplam organik karbon (TOC) içerikleri ve deneme parsellerinden alınan toprak örneklerinin mikromorfolojik özellikleri irdelenmiştir. Araştırma sonuçlarında badem biyokömüründe $\% \mathrm{C}, \% \mathrm{H}, \% \mathrm{~N}$ ve $\% \mathrm{~S}$ değerleri tütün biyokömürüne göre daha yüksek düzeyde saptanmıştır. Tütün biyokömüründe $\mathrm{EC}$, $\mathrm{pH}$ ve $\mathrm{CaCO}_{3}$ değerleri badem biyokömürüne göre daha yüksek düzeyde belirlenmiştir. Badem biyokömüründe $\mathrm{Ca}, \mathrm{Mg}$ ve $\mathrm{Zn}$ içerikleri, tütün biyokömüründe ise Fe ve Cu miktarları daha yüksek düzeyde elde edilmiştir. Mikromorfolojik açıdan tütün biyokömürü kullanılan parseldeki (ANS 5) agregatlaşma diğer parsellere göre farklı düzeyde gözlemlenmiştir. Tütün ve badem biyokömüründe morfolojik olarak deformasyon düzeyi diğer biyokömür ve gübre ilave edilen parsellere göre daha fazla düzeyde olup, buna bağı olarak daha fazla yüzey alanı oluşturma potansiyeline sahip olduğu belirlenmiştir. Bitki yetiştiriciliği ve toprak verimliliği açısından badem biyokömürünün tütün biyokömürüne göre daha iyi özelliklere sahip olduğu belirlenmiştir.

Anahtar Kelimeler: Anason, Atık yönetimi, Yenilenebilir enerji, Biyokömür

\section{ABSTRACT}

Received Date

14.05.2019

Accepted Date:

17.09.2019

(C) Copyright 2018 by Harran University Faculty of Agriculture. Available on-line www.dergipark.gov.tr/harranziraat
In an era where the concept of agricultural sustainability is becoming more and more important, matters such as recycling of biomass, which is used as a source of renewable energy, and waste management are starting to become prominent. Hence, this study is examining the elementary characteristics of biomass obtained from tobacco and almond residues applied to soil, and its micromorphologic effect on soil. The study has been conducted with three repetitions under field conditions, with 5 parcels in each block. Two of these parcels have been applied with tobacco, two with biochar and one with chemical fertiliser to grow aniseed plant (Pimpinella anisum L.). During the trial, elementary, total carbon (TC), inorganic carbon (IC), total organic carbon (TOC) contents of the biochars (tobacco and almond) and the micromorphologic characteristics of the soil samples taken from the parcels have been analysed. Study outcomes have indicated higher $\mathrm{C} \% \mathrm{H} \%, \mathrm{~N} \%$ and $\mathrm{S} \%$ values for almond biochar when compared to tobacco biochar. $\mathrm{EC}, \mathrm{pH}$ and $\mathrm{CaCO} 3$ values have been found to be higher in tobacco biochar than in almond biochar. $\mathrm{Ca}, \mathrm{Mg}$ and 
$\mathrm{Zn}$ contents were higher in almond biochar while Fe and $\mathrm{Cu}$ contents were higher in tobacco biochar. In micromorphologic terms, the aggregation in the parcel (ANS 5) where tobacco biochar was used, has been observed to be at a different level than the other parcels. In tobacco and almond biochar, the morphologic deformation level has been higher than the parcels applied with other biochar and fertiliser, hence it has been determined to have a potential of forming a greater surface area. It has been concluded that almond biochar have better plant cultivation and soil fertility characteristics compared to almond biochar.

Key Words: Aniseed, Waste management, Renewable energy, Biochar

\section{Giriş}

Tarım topraklarının yanlış kullanımı ve bilinçsiz uygulamalar toprak organik maddesinin azalmasına neden olmaktadır. Toprakların verimliliğinde her geçen gün azalan kayıplar artan dünya nüfusu için endişe verici boyutlara erişmektedir. Bugün küresel ısınma gibi nedenlere bağlı doğanın ve iklimlerin değişmesi neticesinde, tarım toprakları bünyelerinde bitki büyümeye etkili olan bitki besin elementlerini tutamaz hale gelerek verimsizleşme sürecine girmiştir. Bunun başlıca sebepleri arasında "organik maddenin" gündün güne azalması gelmekte olup, böylece bu tip toprakların kaliteleri de düşmektedir (Bellitürk, 2016). Toprak kalitesi güçlü ve sürdürülebilir gıda sisteminin temelini oluşturmaktadır. Birim alandan elde edilen ürün düzeyini artırmak iyi bir arazi yönetimi ve bitkinin gelişebileceği besin döngüsüne sahip ortam koşullarının sağlanmasına bağlıdır. Toprak sağlığını iyileştirmek, toprak verimliliğini artırmak ve toprak karbonunu tutmak amacıyla topraklara uygulanan biyokömür bu döngüde önemli bir bileşendir (Krishnakumar ve ark., 2014)

Biyokömür, biyokütlenin pirolizi ile elde edilen karbonca zengin bir katı üründür. Ayrıca biyokömür, temel olarak oksijeniz bir ortamda pirolize olan bitki artıkları veya hayvan gübrelerinden üretilir. Biyokömür topraklarda strüktür, tekstür, gözeneklilik, parçacık boyut dağılımı ve yoğunluk gibi parametreleri etkileyebilir. Ayrıca, dünyada toprak özelliklerinin iyileştirilmesi, sera gazı emisyonlarının azaltılması, topraktan ağır metallerin tutulması üzerine etkisi, yüzey alanı, mineral yapısı, elektriksel iletkenlik, pH gibi parametrelerle ilgili birçok araştırma bulunmaktadır (Cao ve Harris, 2010; Chan ve ark., 2008; Cantrell ve ark., 2012).
Biyokütle tipi, yaşı, bileşenleri (selüloz, yarı selüloz, lignin ve ekstraktifler), bitki türleri, bitkilerin bölümleri ve bitki türlerinin toprak-havasudan belirli bileşikleri alma ve bitki dokularına taşıma/depolama işlemleri gibi bazı farklııılar biyokömürün karakteristik özelliklerini doğrudan ve dolaylı olarak etkiler (Tiftik, 2006; Abdullah ve ark., 2010; Veiga ve ark., 2017). Bu farklılıklar devamında biyokömürün elementel özellikleri kimyasal yapı ve bileşimleri, yüzey alanı, sahip oldukları minerallerin doğal yapısına bağlıdır. Ayrıca biyokütle içindeki temel mineral elementlerin tür ve miktarlarının tanımlanması, yanmadan önce ham madde içindeki bu bileşenlerin seviyeleri ile doğrudan ilişkili olabilir (Lehmann ve Rondon, 2006). Biyokömürün toprak koşulları üzerindeki etkilerinin kapsamı ve diğer elementel özelliklerin bilinmesi mikromorfolojik açıdan agregatların arazi işleme üzerine ve kullanılan organik ve inorganik gübrelerin toprak yapısına etkilerinin araştırılması ve tanımlanması yönünden önemlidir (Burns, 2014).

Bu çalışmayla, yarı kurak şartlar altında anason bitkisi yetiştirilerek toprak kalitesi ve verimlilik düzeyini arttırmak adına kullanılan tütün ve badem biyokömürlerinde kimyasal özelliklerin toprak mikromorfolojisi açısından değerlendirilmesi amaçlanmıştır.

\section{Materyal ve Metot}

\section{Materyal}

Araştırma, Adıyaman ili Kahta ilçesinde Kahta Meslek Yüksekokulu araştırma ve uygulama alanında yapılmıştır. Çalışma alanının denizden yüksekliği 662 m'dir. Kahta'nın uzun yıllar sıcaklık ortalaması $17.4{ }^{\circ} \mathrm{C}$, ortalama yağıs miktarı ise 504.7 mm'dir. Bölge toprakları kireçli ve kil düzeyi oldukça yüksektir (KHGM, 1997). Toprak derinliği 
yaklaşık 0-60 cm'dir. Daha önce deneme alanında yapılan çalışmalarda yaygın birincil mineraller kuvars, feldspat ve mika olup, yaygın kil minerali ise smektit, bunu sırasıyla azalan düzeylerde illit ve kaolinit izlemektedir (Çelik ve Akça, 2017).

\section{Metot}

Çalışma, Adıyaman Üniversitesi Kahta Meslek Yüksekokulu tarımsal araştırma ve uygulama alanında tarla koşullarında, her blokta 5 parsel oluşturulmuş, bu parsellerden ikisine tütün, ikisine badem biyokömürü, bir tanesine dekara 5 kg saf etkili madde gelecek şekilde 20 - 20 - 0 ve 2.5 $\mathrm{kg}$ saf azot gelecek şekilde üst gübre olarak üre kimyasal gübrelemesi yapılmıştır. Deneme yeri toprak özelliklerine ait, deneme öncesi ve sonrası toprak örneklerinin bazı özellikleri Çizelge 1 ve 2 'de verilmiştir. Bloklardaki tütün ve badem biyokömürü uygulanan birer parsel ile kimyasal gübre parsellerine dekara $2 \mathrm{~kg}$ tohum gelecek şekilde anason ekimi yapılmıştır. Tütün ve badem biyokömürü uygulanan birer parsele ise kontrol amacıyla tohum ekimi yapılmamıştır.

Çizelge 1. Deneme öncesi bazı toprak özelliklerine ilişkin sonuçlar

Table 1. Results of some soil properties before the experiments

\begin{tabular}{|c|c|c|c|}
\hline Tekstür (\%), Texture (\%) & & & \\
\hline Kum, Sand & 38.1 & & \\
\hline Silt , Silt & 26.7 & & \\
\hline Kil, Clay & 35.2 & & \\
\hline $\mathrm{CaCO}_{3} \quad(\%)$ & 1.38 & Fosfor $\left(\mathrm{P}_{2} \mathrm{O}_{5}\right)\left(\mathrm{kg} \mathrm{da}^{-1}\right)$, Phosphorus $\left(\mathrm{kg} \mathrm{da}^{-1}\right)$ & 1.32 \\
\hline Organik madde (\%), Organic matter (\%) & 1.66 & Potasyum $\left(\mathrm{K}_{2} \mathrm{O}\right)\left(\mathrm{kg} \mathrm{da}^{-1}\right)$, Potassium $\left(k g d a^{-1}\right)$ & 134.38 \\
\hline Organik karbon (\%), Organic carbon (\%) & 0.96 & $\operatorname{Demir}(\mathrm{Fe})\left(\mathrm{mg} \mathrm{kg}^{-1}\right)$, Iron $\left(\mathrm{mg} \mathrm{kg}^{-1}\right)$ & 8.96 \\
\hline $\mathrm{EC}\left(\mathrm{dS} \mathrm{m^{-1 } )}\right.$ & 0.55 & Çinko (Zn) $\left(m g ~ k g^{-1}\right), \operatorname{Zinc}\left(m g k g^{-1}\right)$ & 0.29 \\
\hline Azot (N) (\%), Nitrogen (\%) & 0.42 & Bakır (Cu) $\left(\mathrm{mg} \mathrm{kg}^{-1}\right)$, Copper $\left(\mathrm{mg} \mathrm{kg}^{-1}\right)$ & 0.79 \\
\hline $\mathrm{pH}$ & 7,51 & Mangan (Mn) $\left(\mathrm{mg} \mathrm{kg}^{-1}\right)$, Manganese $\left(\mathrm{mg} \mathrm{kg}^{-1}\right)$ & 15.62 \\
\hline
\end{tabular}

Çizelge 2. Uygulama sonrası toprakların bazı fiziksel ve kimyasal özellikleri (Çelik ve ark., 2018)

Table 2. Some physical and chemical properties of soils after application (Çelik and et al., 2018)

\begin{tabular}{|c|c|c|c|c|c|c|c|c|c|}
\hline \multirow{3}{*}{$\begin{array}{l}\text { Uygulamalar } \\
\text { Applications }\end{array}$} & \multicolumn{3}{|c|}{ Tekstür (\%) } & \multirow{3}{*}{$\begin{array}{l}\text { Sinıfi } \\
\text { Class }\end{array}$} & \multirow[t]{3}{*}{$\mathrm{pH}$} & \multirow{3}{*}{$\begin{array}{c}\mathrm{CaCO}_{3} \\
(\%)\end{array}$} & \multirow{3}{*}{$\begin{array}{l}\text { OM } \\
(\%)\end{array}$} & \multirow{3}{*}{$\begin{array}{l}\mathrm{OC} \\
(\%)\end{array}$} & \multirow{3}{*}{$\begin{array}{c}E C \\
\left(\mathrm{dS} \mathrm{m}^{-1}\right)\end{array}$} \\
\hline & Kum & Silt & Kil & & & & & & \\
\hline & Sand & Silt & Clay & & & & & & \\
\hline BBA & 38.2 & 26.5 & 35.3 & $\mathrm{CL}$ & 7.45 & 1.43 & 1.88 & 1.09 & 0.72 \\
\hline TBA & 38.1 & 26.7 & 35.2 & $\mathrm{CL}$ & 7.34 & 1.23 & 1.66 & 0.97 & 0.68 \\
\hline KGA & 38.1 & 26.5 & 35.4 & $\mathrm{CL}$ & 7.44 & 1.07 & 2.19 & 1.27 & 0.75 \\
\hline BB & 38.2 & 26.6 & 35.2 & $\mathrm{CL}$ & 7.44 & 1.09 & 2.07 & 1.20 & 0.59 \\
\hline TB & 38.2 & 26.6 & 35.2 & $\mathrm{CL}$ & 7.48 & 1.42 & 2.16 & 1.25 & 0.70 \\
\hline
\end{tabular}

BBA: Badem Biyokömür Anason, Almond biochar aniseed, TBA: Tütün Biyokömür Anason, Tobacco biochar aniseed, KGA: Kimyasal Gübre Anason, Chemical fertiliser aniseed, BB: Badem Biyokömür, Almond biochar, TB: Tütün Biyokömür, Tobacco biochar, CL: Killi Tın, Clay Loam OM: Organik madde, Organic matter, OC: Organik karbon, Organic carbon, EC: Elektriksel iletkenlik, Electric conductivity

Tütün ve badem tarımı yapılan alanlardan hasat sonrası elde edilen artıklar fırında $420{ }^{\circ} \mathrm{C}^{\prime}$ de 30 dakikada oksijensiz koşullarda yakılarak biyokömür (biochar) elde edilmiştir. Toprak reaksiyonu $(\mathrm{pH})$ ve elektriksel iletkenliği (EC) (1:25 $w / v$ ve $1: 5 \mathrm{w} / \mathrm{v}$ sırası ile) diyonize su ile ölçülmüş (Richards, 1954) ve $\mathrm{CaCO}_{3}$ analizi yapılmıştır (Allison ve Moodie, 1965). Tütün ve badem biyokömürlerinin elementel özellikleri Thermo marka flash 2000 model ve toplam organik karbon içerikleri Shimadzu marka TOC-L SSM-5000A model (total organic carbon analyzer) cihazları ile (Adıyaman Üniversitesi Merkezi Araştırma Laboratuvarı) gerçekleştirilmiştir. Toprak ve biyokömür (tütün ve badem) örnekleri Harran Üniversitesi Merkezi Araştırmalar laboratuvarında polarize mikroskopta ve tarama elektron mikroskobunda (SEM ve EDAX) incelenmiş ve ürünün mikro-yapısal gelişimi ve gözenek boyut ve dağılım özellikleri irdelenmiştir (FitzPatrick, 1993). 


\section{Araştırma Bulguları ve Tartışma}

Tütün ve badem biyokömürlerinin bazı kimyasal analizlerinin değerlendirilmesi

Elementel analiz, biyokömür karakterizasyonu için hızlı, kullanışlı ve yaygın olarak kullanılan bir tekniktir. Her tür biyokütleden pirolizle elde edilen biyokömür materyalinde önemli miktarda karbon, hidrojen ve oksijen bulunur. Biyokömürün özelliklerini belirlemek için kullanılan elementel analiz uygun bir yöntem olmasına rağmen (Enders ve ark., 2012; McBeath ve ark., 2015), bunun için henüz uluslararası standart bulunmamaktadır (Bird ve ark., 2017). Bazı biyokütleler çoğu organik maddeye ve yaygın olarak kullanılan standartlara göre çok yüksek karbon içeriğine ( $>$ ağırlık olarak $\% 80$ ) sahiptir.

Kullanılan biyokömürlerin elementel analiz sonuçları Çizelge 3'de verilmiştir. Badem biyokömüründe $\% \mathrm{C}, \% \mathrm{H}, \% \mathrm{~N}$ ve $\% \mathrm{~S}$ değerleri tütün biyokömürüne daha yüksek düzeyde saptanmıştır. Badem biyokömüründe $N$ ve $S$ elementlerinin yüksek düzeyi asitlik karakterini ön plana çıkartmaktadır. Bu nedenle badem biyokömürünün daha çok yüksek $\mathrm{pH}$ içeriğine sahip topraklara uygulanması gerçeğini ortaya koymaktadır. Badem biyokömürü ile ilgili yapılan çalışmalarda \% C ve \% $\mathrm{H}$ düzeyleri elde ettiğimiz sonuçlardan yüksek düzeyde saptanırken, $\% \mathrm{~N}$ ve \% S değerleri düşük düzeyde belirlenmiştir (Mohammed, 2018). Akalın ve Karagöz (2011)' ün tütün sapı ve tozunun biyokömürleriyle ilgili yaptıkları çalışmada, \% C sonuçları bulgularımızla uyum halindeyken, $\% \mathrm{H}$ ve $\% \mathrm{~S}$ içerikleri bulgularımızdan yüksek, $\% \mathrm{~N}$ değerlerinin ise daha düşük olduğunu bildirmişlerdir. Bulgularımızdaki bu farklılıkların kullanılan bitki materyallerinden veya piroliz yönteminden kaynaklandığı tahmin edilmektedir. Tütün biyokömüründe $\mathrm{EC}, \mathrm{pH}$ ve $\mathrm{CaCO}_{3}$ değerleri, badem biyokömürüne göre daha yüksek düzeyde belirlenmiştir (Çizelge 3). Kurak ve yarı kurak iklim koşullarına sahip toprakların yüksek pH içeriği nedeniyle bu tür alanlarda badem biyokömürünün, düşük toprak reaksiyonuna sahip topraklarda ise tütün biyokömürünün düşünülmektedir. Toprak reaksiyonu alkali, kireçli, kurak ve yarı kurak iklime sahip bölge topraklarında badem biyokömürünün toprak reaksiyonunu düşürmesi ve dengelemesi açısından, tütün biyokömürüne göre daha olumlu sonuçlar verebileceği kanısına varılabilir. Yapılan araştırmalarda bitki gelişimine en olumlu etkinin pH'sı en düşük olan biyokömür ilavesi ile yapıldığı görülmüş olup, bu nedenle piroliz koşullarının $\mathrm{pH}^{\prime} \mathrm{yı}$ yükseltmeyecek şekilde ayarlanmasının önemi vurgulanmıştır (Taghizadeh-Toosi ve ark., 2012).

Çizelge 3. Tütün ve badem biyokömürlerinin bazı kimyasal özellikleri

Table 3. Some chemical properties of tobacco and almond biochar

\begin{tabular}{ccc}
\hline $\begin{array}{c}\text { Özellikler } \\
\text { Properties }\end{array}$ & $\begin{array}{c}\text { Tütün biyokömürü } \\
\text { Tobacco biochar }\end{array}$ & $\begin{array}{c}\text { Badem } \\
\text { biyokömürü } \\
\text { Almond biochar }\end{array}$ \\
\hline$\% \mathrm{C}$ & 46,21 & 46,54 \\
$\% \mathrm{H}$ & 2,88 & 4,44 \\
$\% \mathrm{~N}$ & 1,68 & 3,07 \\
$\% \mathrm{~S}$ & 0,00 & 1,63 \\
$\mathrm{pH}$ & 10 & 7.8 \\
$\mathrm{EC}\left(\mu \mathrm{cm}^{-1}\right)$ & 1515 & 561 \\
$\mathrm{CaCO}_{3}(\%)$ & 27.57 & 5.54 \\
\hline
\end{tabular}

Jeffery ve ark. (2017) yüksek pH'sı nedeni ile biyokömürün bu topraklarda fazla kireçleme etkisi ile $\mathrm{pH}^{\prime}$ nın gereğinden fazla yükselmesine neden olduğunu bununda $\mathrm{Mn}, \mathrm{Fe}, \mathrm{B}$ ve $\mathrm{P}$ gibi besin elementlerinin alımını engelleyebileceğini bildirmişlerdir. Tütün biyokömürünün tuzluluk düzeyi, badem biyokömürüne göre yaklaşık 3 kat daha yüksek düzeyde saptanmıştır. Tuzluluk içeriği yüksek olan tütün biyokömürünün yağışı bölge topraklarında kullanılması önerilmektedir. $\mathrm{Bu}$ biyokömürün bazik karakterli topraklarda kullanılması mevcut düzeyi daha da artırabileceği ve bu nedenle alkali reaksiyona sahip topraklarda kullanılmaması gerektiği sonucuna varılmıştır (Çizelge 3). Daha önce Çelik ve ark. (2018) tarafından yapılan çalışmada anason bitkisi uygulanmayan ve tütün biyokömürü kullanılan alanda en yüksek tuz içeriği saptanmıştır. Elde edilen sonuçlar tütün biyokömürünün toprak koşulları üzerindeki etkileşiminin doğruluğunu ortaya koymaktadır. Yağışlı iklimsel özelliklere sahip asit karakterli topraklarda tütün 
biyokömürünün toprak asitliliğini azaltması ve bunun yanında toprak için kullanılacak gübre ihtiyacını azaltabileceği ve verimliliği arttırabileceği düşünülmektedir. Tütün ve badem biyokömürlerinin kireç içerikleri irdelenecek olursa, tütün biyokömürünün kireç içeriği badem biyokömürüne göre daha fazla düzeyde saptanmıştır (Çizelge 3). Bu sonuca göre, kireçli kurak ve yarı kurak bölge topraklarında badem biyokömürünün üretim ve verimliliği sınırlayıcı herhangi bir etkiye sahip olmadığını ortaya koymaktadır.

Tütün ve badem biyokömürlerinin bazı besin elementleri açısından değerlendirilmesi

Tütün ve badem biyokömürlerinin besin elementi içerikleri irdelendiğinde, badem biyokömüründe $\mathrm{Mg}, \mathrm{Cu}$ ve $\mathrm{Zn}$ içerikleri, tütün biyokömüründe ise $\mathrm{Ca}$ ve $\mathrm{Fe}$ miktarları daha yüksek düzeyde saptanmıştır (Çizelge 4). Tütün biyokömüründe $\mathrm{Ca}$ içeriğinin yüksek belirlenmesi biyokömüre bazik karakter kazandırabileceğinin göstergesidir. Bunun için asit karakterli topraklarda kullanılması önerilebilir. Biyokömürün toprağın verimliliği üzerine olan etkisi, toprakta bulunan yarayışlı besin elementlerinin düzeyi, yarayışlılığı (Günal ve Erdem, 2018; Lehmann ve ark., 2003) ve biyokimyasal özelliklere olan (Luo ve $\mathrm{Gu}, 2016)$ etkisi ile ilişkilidir.

Çizelge 4. Tütün ve badem biyokömürlerinin bazı besin elementi içerikleri

Table 4. Some nutrient contents of tobacco and almond biochar

\begin{tabular}{ccc}
$\begin{array}{c}\text { Besin maddeleri } \\
\text { içeriği }\end{array}$ & $\begin{array}{c}\text { Tütün } \\
\text { biyokömürü } \\
\text { Tobacco } \\
\text { biochar }\end{array}$ & $\begin{array}{c}\text { Badem } \\
\text { biyokömürü } \\
\text { Almond biochar }\end{array}$ \\
\hline $\mathrm{Ca} \mathrm{( \% )}$ & 3.7 & 3.5 \\
$\mathrm{Mg} \mathrm{( \% )}$ & 2.1 & 3.3 \\
$\mathrm{Fe} \mathrm{( \% )}$ & 4.2 & 2.1 \\
$\mathrm{Zn} \mathrm{( \% )}$ & 1.6 & 10.2 \\
$\mathrm{Cu}(\%)$ & 2.1 & 5.9 \\
\hline
\end{tabular}

Toprağa verilen biyokömürlerin hareketsiz (immobil) metallere farklı etkileşimlerde bulunabileceği belirlenmiştir. Bazik karakterli biyokömürler toprağa uygulandığında toprak reaksiyonunu artırarak besin maddelerinin alınabilirliğini azalttığı bildirilmiştir (Peng ve ark., 2011). Yüksek karbon içeriği nedeni ile biyokömür toprağa ilave edildiğinde ayrışma ve parçalanma sonucunda açığa çıkan alkol, karboksil ve karbonil gruplar nedeni ile topraktaki negatif yükleri artırmaktadır (Sakin ve Yanardağ, 2019). Ayrıca farklı sıcaklıklarda üretilen biyokömürler farklı düzeyde karbon miktarlarına sahiptir.

Çelik ve ark. (2018)'nın yaptıkları çalışmada, toprağa uygulanan biyokömür kontrol grubu ile karşılaştırıldığında toprak bitki besin maddelerinden $\mathrm{P}, \mathrm{Zn}$ miktarını çok önemli düzeyde artırmışken, diğer elementlerde fazla bir değişiklik izlenmediğini, en fazla $P$ artışının kimyasal gübre atılan parselde belirlendiğini, en düşük ise badem biyokömüründe saptandığını, biyokömür uygulaması yapılan parsellerde en yüksek Zn değerlerinin badem biyokömürü, en düşük değerlerin ise tütün biyokömürünün kullanıldığı anason parsellerinden alındığını bildirmişlerdir. Bulgularımızda badem biyokömürünün $\quad \mathrm{Zn}$ düzeyinin tütün biyokömürüne göre daha yüksek saptanması önemli bir kanıt olarak gösterilebilir. Güneydoğu Anadolu Bölgesi topraklarında Zn'nun düşük oluşunun nedenini Kızılgöz ve ark. (2011)'ları yüksek toprak $\mathrm{pH}^{\prime}$ sı ile karbonatlı çökel kökenli ana materyalin üzerinde gelişen topraklardan kaynaklanabileceğini bildirmişlerdir. Bu nedenle Zn eksikliği görülen bahçe ve tarla tarımı yapılan alanlarda badem biyokömürünün kullanımı daha uygun olacaktır.

Yağışlı ve sıcak iklime sahip bölge topraklarında fazla miktarda biyokömür ilavesi durumunda $\mathrm{P}, \mathrm{K}$, $\mathrm{Ca}, \mathrm{Zn}$ ve $\mathrm{Cu}$ gibi elementlerin bitkilerce alınabilirliğini artırdığı belirtilmiştir (Lehmann ve Rondon, 2006; Steiner ve ark., 2007). Yapılan çalışmalarda bu tür elementlerin düzeylerinin artması için farklı biyokömür ve dozlarının uygulanmasına ihtiyaç olduğu bildirilmektedir (Namgay ve ark., 2010). Elde ettiğimiz bulgularda tütün biyokömüründeki $\mathrm{Fe}$ düzeyi, badem biyokömürüne göre yaklaşık 2 kat daha fazla saptanmıştır. Çelik ve ark. (2018)'larının yapmış oldukları çalışmada bitkisiz tütün biyokömürü uygulanan alanda en yüksek değerin elde edilmesi 
bulgularımızı doğrulamaktadır. Tütün ve badem biyokömürlerinin kimyasal özellikleri içerisinde dikkat çekici farklılıklardan biride $\mathrm{Cu}$ düzeyidir. Araştırma sonuçlarına göre badem biyokömüründeki Cu düzeyi tütün biyokömürüne göre yaklaşık 3 kat daha fazla düzeyde saptanmıştır (Çizelge 4). Organik atıkların mikrobiyal ayrışması sırasında oluşan veya canlı kökler tarafından salgılanan, küçük moleküllü kompleks yapıcılar, adsorbe edilmiş bakırla kompleks oluşturarak hareketli hale getirirler. Bu yolla, çözünebilen bakır miktarını önemli miktarda yükseltirler (Sönmez ve ark., 2006). Bu açıdan değerlendirildiğinde badem biyokömürünün ayrışmanın yoğun olduğu iklimsel özelliklere sahip bölge topraklarında kullanılmasının daha rasyonel olacağı düşünülmektedir. Çelik ve ark. (2018) badem ve tütün biyokömürü uyguladıkları anasonda verim ve bitkisel özellikler yönünden badem biyokömürünün daha iyi sonuçlar verdiğini bildirmişlerdir.

Tütün ve badem biyokömürlerinin toplam organik, inorganik ve toplam karbon analizlerinin değerlendirilmesi

Tütün ve badem biyokömürlerinin toplam organik ve inorganik karbon düzeyleri Çizelge 5' de verilmiştir. Badem biyokömüründe belirlenen toplam organik karbon ve toplam karbon düzeyleri tütün biyokömürüne göre daha yüksek düzeyde saptanmıştır. Ancak İnorganik karbon içeriğinin tütün biyokömüründe daha yüksek olduğu belirlenmiştir. Biyokömürlerin içerdiği organik karbon düzeyini piroliz sıcaklığı, reaksiyon süresi, reaktiflerin konsantrasyonu ve biyokömür karbonizasyon derecesi etkiler (Knicker ve ark., 2007). Çoğu biyokömür $C$ ve aromatik $C$ yapıları bakımından zengin olan kimyasal yapısı nedeniyle çok kararlı olup (Baldock ve Smernik, 2002; Calvelo Pereira ve ark., 2011) mikrobiyal bozunmaya karşı oldukça dirençlidir. Elde ettiğimiz elementel analiz bulgularında badem biyokömürünün \% C içeriği tütün biyokömürüne göre yüksek düzeyde belirlenmesi, toplam organik karbon analizlerinin doğruluğunu kanıtlamaktadır. Yarı kurak bölge topraklarında yağışın düşük, sıcaklığın yüksek düzeyde olması ayrışmanın artmasına ve biriken karbon miktarının azalmasına neden olmaktadır. Bu açıdan ilimizde yaygınlaşan badem tarımından elde edilen atıkların değerlendirilmesi gerekmektedir.

Çizelge 5. Tütün ve badem biyokömürlerinde toplam organik karbon, toplam karbon ve inorganik karbon içerikleri

Table 5. Total organic carbon, total carbon and inorganic carbon Contents in tobacco and almond biochar

\begin{tabular}{ccc}
\hline $\begin{array}{c}\text { Parametreler } \\
\text { Parameters }\end{array}$ & $\begin{array}{c}\text { Tütün } \\
\text { biyokömürü } \\
\text { Tobacco biochar }\end{array}$ & $\begin{array}{c}\text { Badem } \\
\text { biyokömürü } \\
\text { Almond biochar }\end{array}$ \\
\hline TOC \% & 0.389 & 0.495 \\
TC \% & 0.406 & 0.498 \\
IC \% & 0.017 & 0.002 \\
\hline
\end{tabular}

TOC: Toplam organik karbon, TOC: Total organic carbon, TC: Toplam karbon, TC: Total carbon, IC: Inorganik karbon, IC: Inorganic carbon

Özellikle karbon içeriği yüksek biyokömürlerin toprağa uygulanması sonucu, toprakta C'nun uzun süreli tutulması, $\mathrm{CO}_{2}$ emisyonlarının azaltılması ve bunlara ek olarak küresel boyutta çevresel faydalar sağlamaktadır (Qin ve ark., 2016).

\section{Biyokömürlerin kullanıldığı örneklerin mikromorfolojik özellikleri}

Biyokömür'ün yüzeylerindeki ve yapılarındaki değişimleri ve özelliklerini tanımlamak ve incelemek için SEM-EDAX analizleri etkili bir yoldur. Tütün ve badem biyokömürünün toprak koşulları üzerindeki etkilerinin kapsamı Tarama Elektron Mikroskobu (Scanning Electron Microscopy-SEM) ile toprakların mikro-yapısal gelişimi ve gözenek dağılımıyla ilgili özellikler irdelenmiştir (Şekil 1) (FitzPatrick, 1993). Çalışma alanındaki toprakların mineralojik olarak baskın kil tipinin smektit içermesi nedeniyle plastiklik ve agregatlaşmaya olumlu yönde katkı sunmaktadır. Çalışma alanında yaygın kil minerali 2:1 tabakalı smektit olup, bunu sırasıyla azalan düzeylerde illit ve kaolinit izlemektedir (Çelik ve Akça, 2017). Biyokömür kullanılan parsellerde bu etki daha belirgin bir şekilde görülmektedir (Şekil 1). Topraktaki agregatlaşmaya katkı sunan diğer nedenlerden biride kireç ve organik madde içeriğidir (Özdemir ve ark., 2005). Özellikle tütün biyokömürü kullanılan parseldeki (ANS 5) 
agregatlaşma diğer parsellere göre farklı düzeyde belirlenmiştir. Bunun nedeni, tütün biyokömürü kullanılan parsellerdeki kireç ve organik madde düzeyinin daha yüksek düzeyde saptanmasıdır. Toprak agregatlarındaki organik madde katkısı agregatların dayanaklılık düzeyini arttırarak toprağın su, havalanma, verimlilik ve özellikle eğimli alanlarda erozyona karşı direncini artıır (Devine ve ark., 2014; Whalen ve Chang, 2002). Bununla birlikte toprak örneklerinin SEM görüntülerinde organik yapılar belirgin olarak saptanmamasına karşın ANS 1 ve ANS 2 örneğinde zayıf organik yapılar söz konusudur. Söz konusu olgu büyük olasılıkla organik maddenin hızla ayrışarak kalıcı humin formlarına dönüşememesi sonucu gerçekleştiği düşünülmektedir.

Biyokömürlerin SEM görüntülerine göre, gözeneklilik düzeyinin her iki biyokömürde de (tütün ve badem) yüksek düzeyde olduğu saptanmıştır (Şekil 2). Gözeneklilik miktarındaki artış mikrobiyal aktiviteye ev sahipliği yapan mikroorganizmaların sayısındaki artışa paralel olarak artar. Topraktaki canlılık düzeyinin artması toprağa daha fazla miktarda organik maddenin katılması anlamına gelir. Bitki besin elementlerinin toprakta daha kolay tutulmasını sağlar (El-Ramady ve ark., 2014).

\section{ANS 1}
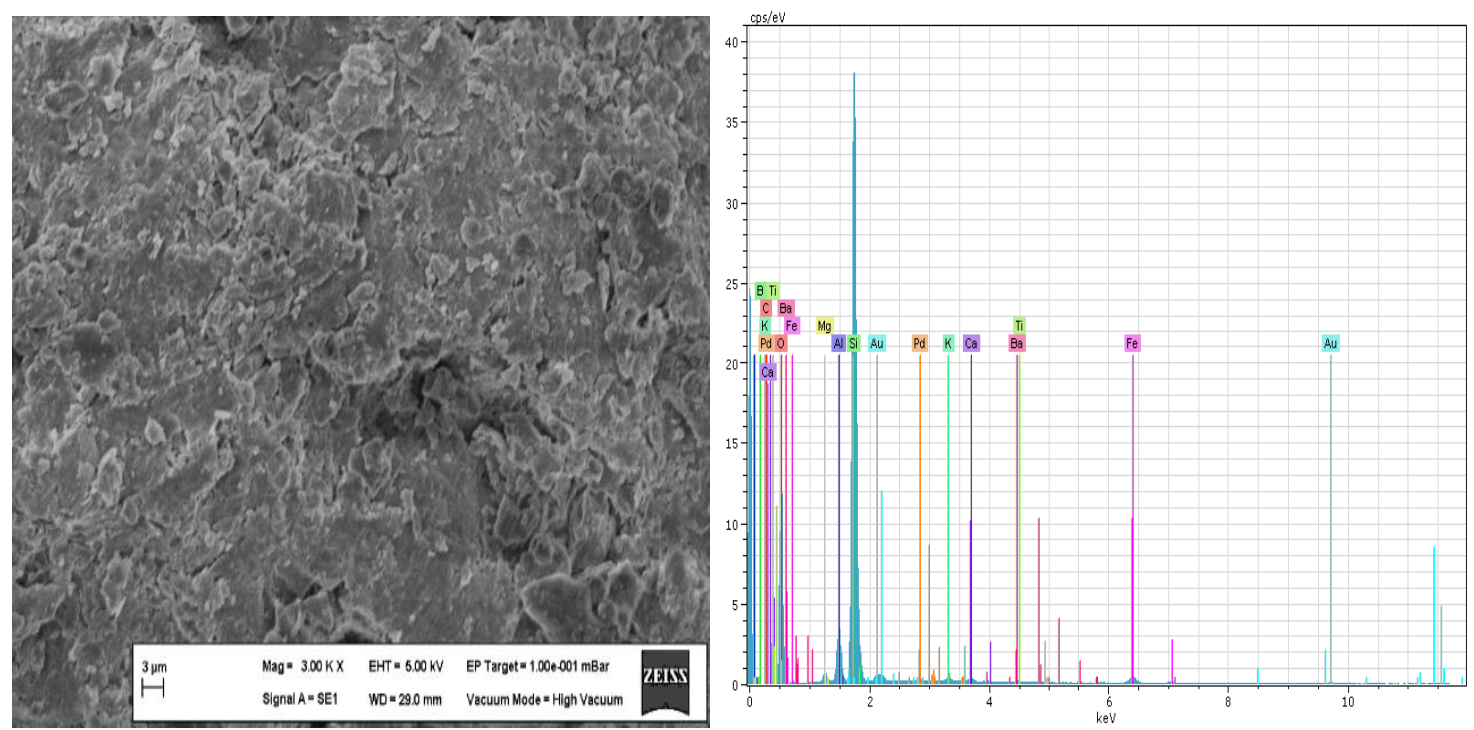

\section{ANS 2}
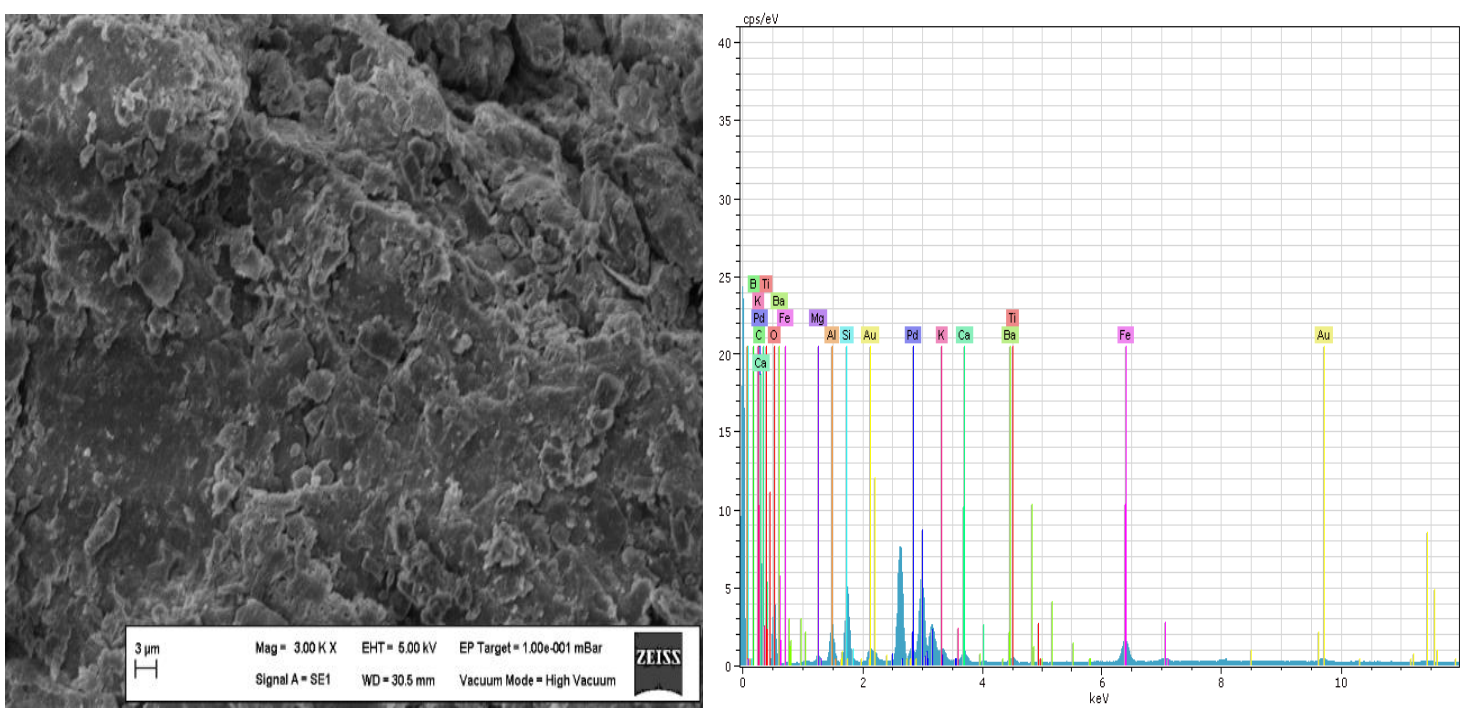
ANS 3
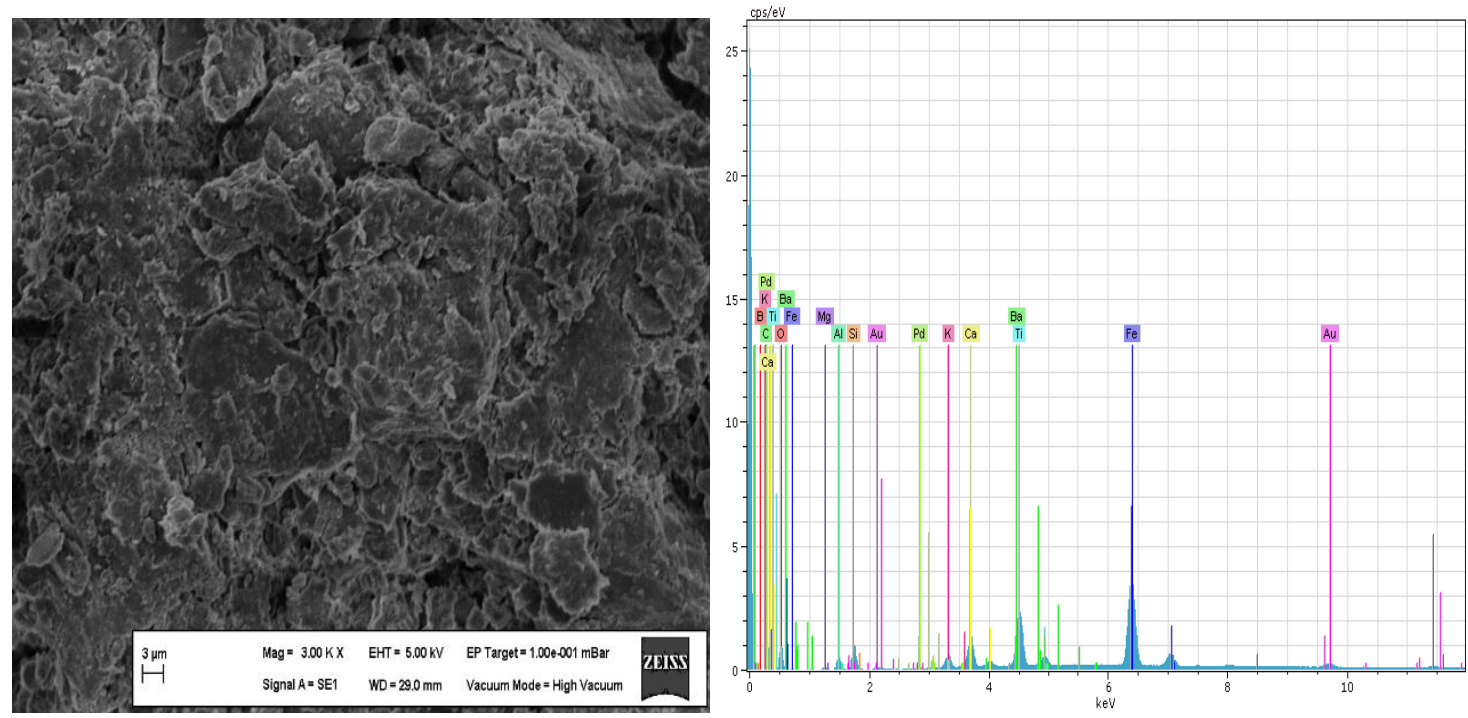

\section{ANS 4}
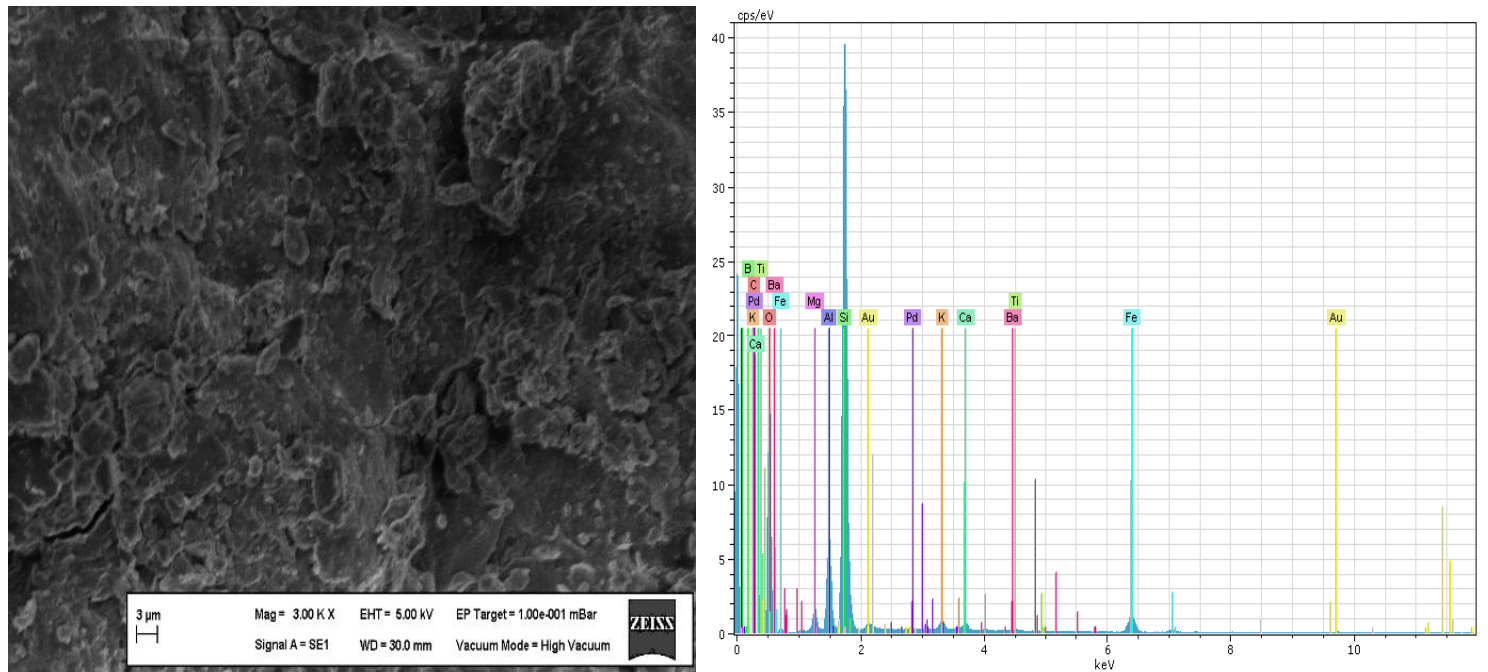

\section{ANS 5}
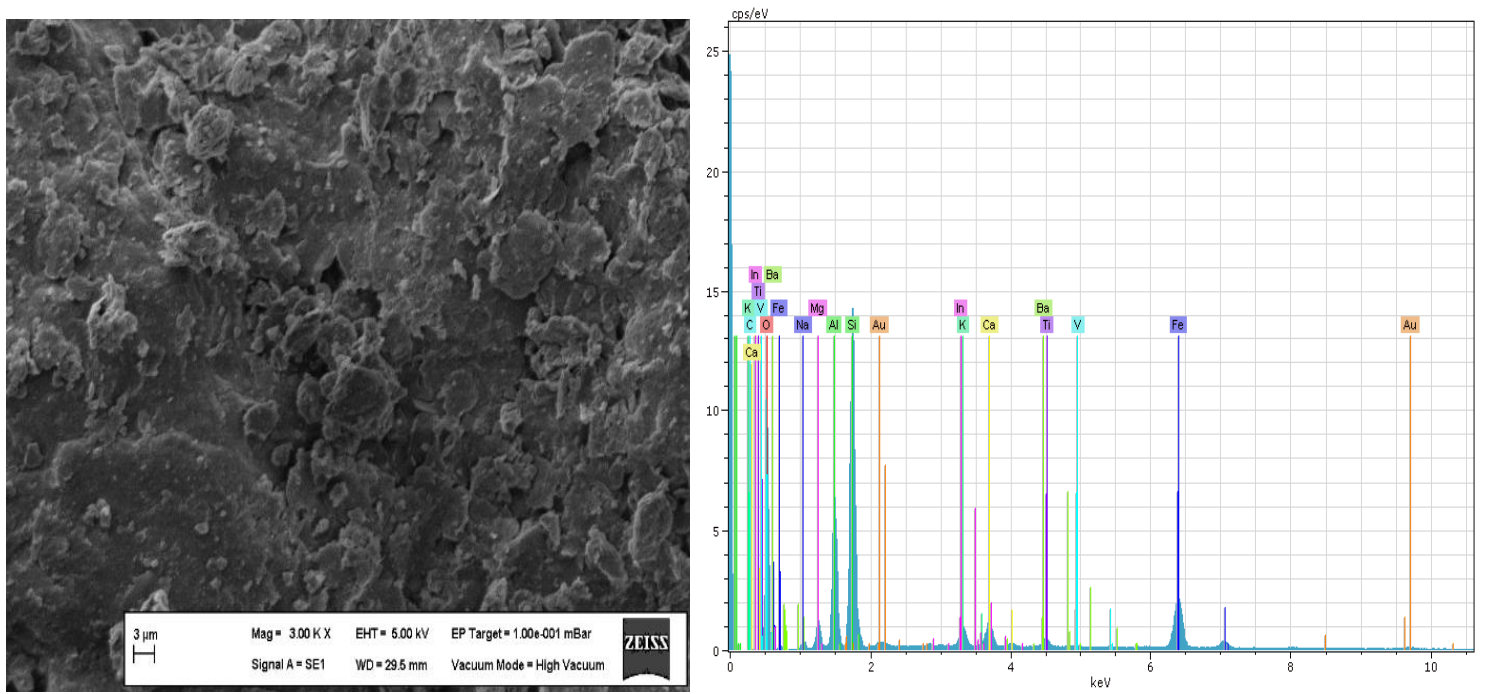

Şekil 1. Deneme alanı topraklarının SEM ve EDAX görüntüleri (ANS 1: Badem biyokömür anason, ANS 2: Tütün biyokömür anason, ANS 3: Kimyasal gübre anason, ANS 4: Bitkisiz toprakta badem biyokömür, ANS 5: Bitkisiz toprakta tütün biyokömür).

Figure 1. SEM and EDAX images trial area territories (ANS 1: Almond biochar aniseed, ANS 2: Tobacco biochar aniseed, ANS 3: Chemical fertiliser aniseed, ANS 4: Almond biochar non-plant soil, ANS 5: Tobacco biochar non-plant soil) 
BB
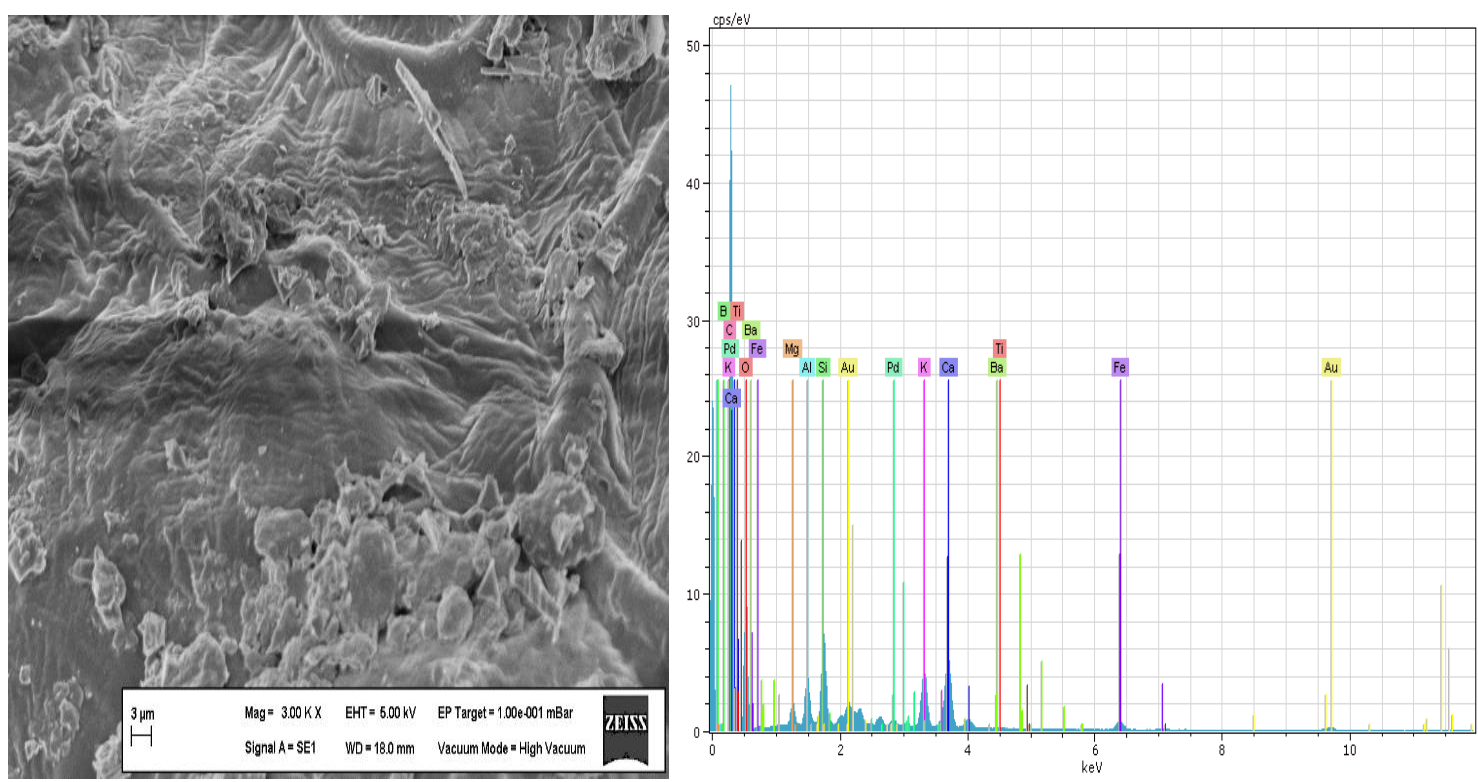

TB
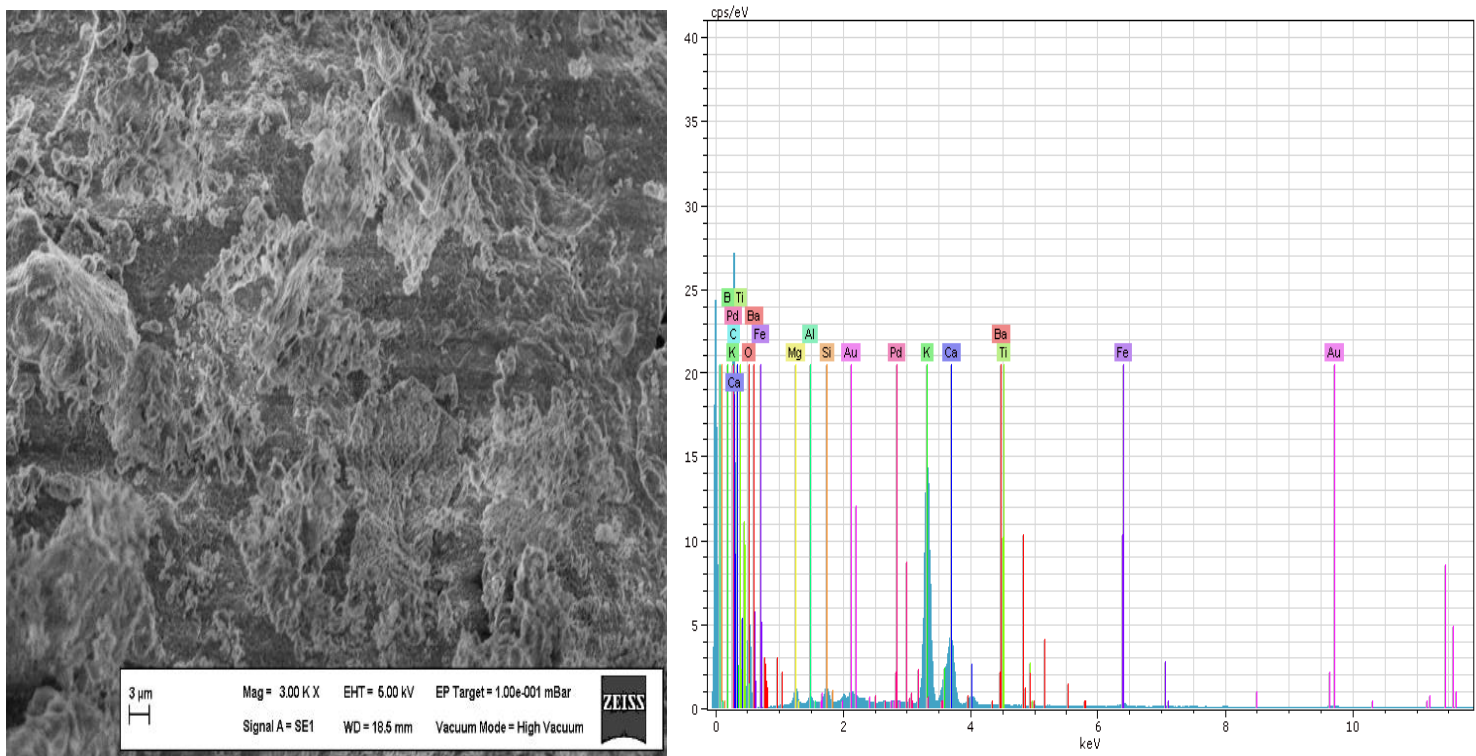

Şekil 2. Deneme alanında kullanılan badem ve tütün biyokömürlerinin SEM ve EDAX görüntüleri (BB: Badem biyokömürü, TB: Tütün biyokömürü).

Figure 2: SEM and EDAX images of almond and tobacco biochar used in the experimental area (BB: Almond biochar, TB: Tobacco biochar)

\section{Sonuçlar}

Badem biyokömürünün tütün biyokömürüne göre, toprak organik maddesini artırdığı ve doğal toprak organik maddesinin mineralizasyonunu etkilediği için tarım arazilerinde kullanılabileceği sonucuna varılmıştır. Topraklara biyokömür uygulanması durumunda toprakların özellikleri (fiziksel, kimyasal, mikromorfolojik vb.) göz önünde bulundurarak yapılmalıdır. Elde ettiğimiz bulgulara göre, özellikle asit karakterli topraklarda tütün biyokömürünün, bazik karakterli topraklarda ise badem biyokömürü uygulanmasının daha iyi sonuçlar vereceği saptanmıştır. Biyokömür kullanımıyla beraber, topraktaki karbonu dengelemek ve topraktaki besin tüketimini azaltmak açısından karbon yönünden zengin atıklar kullanılmalıdır. ilimizde badem tarımının yaygınlaşması ile birlikte bu tür atıkların değerlendirilebileceği bir potansiyel ortaya çıkmaktadır. Araştırma sonucuna göre, gerek bitkisel özellikler gerekse karbon düzeylerinin yüksek saptanması nedeniyle badem biyokömürünün, tütün biyokömürüne göre üstün özelliklere sahip olduğu belirlenmiştir. 


\section{Kaynaklar}

Abdullah, H., Mediaswanti, K. A. \& Wu, H. (2010). Biochar as a fuel: 2. Significant differences in fuel quality and ash properties of biochars from various biomass components of Mallee trees. Energy \& Fuels, 24(3), 1972-1979.

Akalın, M. K. \& Karagöz, S. (2011). Pyrolysis of Tobacco Residue: Part 1. Thermal. Bioresources, 6(2), 15201531.

Allison, L. E. \& Moodie, C. D. (1965). Carbonate. Methods of Soil Analysis. Part 2. Chemical and Microbiological Properties, (methodsofsoilanb), 1379-1396.

Baldock, J. A. \& Smernik, R. J. (2002). Chemical composition and bioavailability of thermally altered Pinus resinosa (Red pine) wood. Org. Geochem. 33:1093$1109 . \quad$ http://dx.doi. org/10.1016/S01466380(02)00062-1.

Bellitürk, K. (2016). Sürdürülebilir Tarımsal Üretimde Katı Atık Yönetimi İçin Vermikompost Teknolojisi. Çukurova Tarım ve Gıda Bilimleri Dergisi, 31 (3): 1-5 (Özel Sayı), Adana.

Bird, M., Keitel, C. \& Meredith, W. (2017). Analysis of biochars for $\mathrm{C}, \mathrm{H}, \mathrm{N}, \mathrm{O}$ and $\mathrm{S}$ by elemental analyser. Biochar: A Guide to Analytical Methods, 39.

Burns, K. J. (2014). The effect of biochar addition on soil structure and changes to aged biochar particles in soil. This thesis is presented fort the Degree of Master of Science at The University of Western Australia, School of Earth and Environment. P. 84-94

Calvelo Pereira, R., Kaal, J., Camps Arbestain, M., Pardo Lorenzo, R., Aitkenhead, W., Hedley, M. \& MaciáAgulló, J. (2011). Contribution to characterisation of biochar to estimate the labile fraction of carbon. Org. Geochem. 42: 1331-1342. http://dx.doi.org/10.1016/j.orggeochem.2011.09.00 2.

Cantrell, K. B., Hunt, P. G., Uchimiya, M., Novak, J. M. \& Ro, K. S. (2012). Impact of pyrolysis temperature and manure source on physicochemical characteristics of biochar. Bioresource technology, 107, 419-428.

Cao, X. \& Harris, W. (2010). Properties of dairy-manurederived biochar pertinent to its potential use in remediation. Bioresource technology, 101(14), 52225228.

Chan, K. Y., Van Zwieten, L., Meszaros, I., Downie, A. \& Joseph, S. (2008). Using poultry litter biochars as soil amendments. Soil Research, 46(5), 437-444.

Çelik, A. \& Akça, E. (2017). Adıyaman'da eğimli akarsu seki topraklarının sürdürülebilir kullanımı için öneriler. Yüzüncü Yıl Üniversitesi Tarım Bilimleri Dergisi, 27(1), 130-141.

Çelik, A., İnan, M. \& Sakin, E. (2018). Tütün ve badem atıklarından elde edilen biyokömürün bazı toprak kalite parametreleri ile anason bitkisinin verimine etkileri, II. Uluslararası Multidisipliner Çalışmalar Kongresi Tam bildiriler kitabı, 353-371.

Devine, S., Markewitz, D., Hendrix, P. \& Coleman, D. (2014). Soil aggregates and associated organic matter under conventional tillage, no-tillage, and forest succession after three decades. PloS one, 9(1):1- 12, e84988.

El-Ramady, H. R., Alshaal, T. A., Amer, M., DomokosSzabolcsy, É., Elhawat, N., Prokisch, J. \& Fári, M.
(2014). Soil quality and plant nutrition. In Sustainable Agriculture Reviews 14 (pp. 345-447). Springer, Cham.

Enders, A., Hanley, K., Whitman, T., Joseph, S. \& Lehmann, J. (2012). Characterization of biochars to evaluate recalcitrance and agronomic performance. Bioresource Technology 114, 644-653. doi:10.1016/j.biortech.2012.03.022.

FitzPatrick, E. A. (1993). Soil Microscopy and Micromorphology. Chichester No. 631.43 F5. John Wiley \& Sons. 433P.

Günal, E. A. \& Erdem, H. (2018). Biyokömür; Tanımı, Kullanımı ve Tarım Topraklarındaki Etkileri. ADÜ Ziraat Derg, 2018;15(2):87-93.

Jeffery, S., Abalos, D., Prodana, M., Bastos, A. C., Van Groenigen, J. W., Hungate, B. A. \& Verheijen, F. (2017). Biochar boosts tropical but not temperate crop yields. Environmental Research Letters, 12(5), 053001.

KHGM, (1997). Adıyaman Kâhta Ovası Sulama Proje Sahası Detaylı Toprak Etütleri, Köy Hizmetleri Genel Müdürlüğü Etüd ve Proje Dairesi Başkanlığı, Ankara, s. 250.

Kızılgöz, ì., Sakin, E. \& Gürsöz, S. (2011). Ovacık Köyü'nde (Şanlıurfa) Yetiştirilen Asma (Vitis vinifera L.) Çeşitlerinin Mineral Beslenme Durumunun Değerlendirilmesi. Uludağ Üniversitesi Ziraat Fakültesi Dergisi, 25(1):1-10.

Knicker, H., Müller, P. \& Hilscher, A. (2007). How useful is chemical oxidation with dichromate for the determination of "Black Carbon" in fire-affected soils? Geoderma 142: 178-196. http://dx.doi.org/10.1016/j.geoderma.2007.08.010.

Krishnakumar, S., Rajalakshmi, A. G., Balaganesh, B., Manikandan, P., Vinoth, C. \& Rajendran, V. (2014). Impact of biochar on soil health. Int. J. Adv. Res, 2(4), 933-950.

Lehmann, J., da Silva, J. P., Steiner, C., Nehls, T., Zech, W. \& Glaser, B. (2003). Nutrient availability and leaching in an archaeological Anthrosol and a Ferralsol of the Central Amazon basin: fertilizer, manure and charcoal amendments. Plant and soil, 249(2), 343357.

Lehmann, J. \& Rondon, M. (2006). Bio-char soil management on highly weathered soils in the humid tropics. Biological approaches to sustainable soil systems, 113(517), e530.

Luo, L. \& Gu, J. D. (2016). Alteration of extracellular enzyme activity and microbial abundance by biochar addition: Implication for carbon sequestration in subtropical mangrove sediment. Journal of environmental management, 182, 29-36.

McBeath, A. V., Wurster, C. M. \& Bird, M. I. (2015). Influence of feedstock properties and pyrolysis conditions on biochar carbon stability as determined by hydrogen pyrolysis. Biomass and Bioenergy 73, 155-173. doi:10.1016/j. biombioe.2014.12.022.

Mohammed, I. Y., Abakr, Y. A. \& Mokaya, R. (2018). Valorisation of adzuki bean waste to biofuel precursors via pyrolysis: kinetics, product distribution and characterisation. Biomass Conversion and Biorefinery, 8(3), 699-710.

Namgay, T., Singh, B. \& Singh, B. P. (2010). Influence of 
biochar application to soil on the availability of As, $\mathrm{Cd}, \mathrm{Cu}, \mathrm{Pb}$, and $\mathrm{Zn}$ to maize (Zea mays L.). Soil Research, 48(7), 638-647.

Ogawa, M., Okimori, Y. \& Takahashi, F. (2006). Carbon sequestration by carbonization of biomass and forestation: Three case studies. Mitigation and Adaptation Strategies for Global Change 11: 429-444

Özdemir, N., Gülser, C., Ekberli, í. \& Özkaptan, S. (2005). Toprak düzenleyicilerinin asit toprakta strüktürel dayanıklılığa etkisi. Atatürk Üniversitesi Ziraat Fakültesi Dergisi, 36(2), 151-156.

Peng, X., Ye, L. L., Wang, C. H., Zhou, H. \& Sun, B. (2011). Temperature- and durationdependent rice straw-derived biochar: characteristics and its effects on soil properties of an ultisol in southern china. Soil Till. Research, 112, 159-166.

Qin, X., Li, Y., Wang, H., Liu, C., Li, J., Wan, Y. \& Liao, Y. (2016). Long-term effect of biochar application on yield-scaled greenhouse gas emissions in a rice paddy cropping system: a four-year case study in south China. Sci. Total Environ. 570: 1390-1401. http://dx.doi.org/10.1016/j.scitotenv.2016.06.222.

Richards, L. A. (1954). Diagnosis and improvements saline and alkali soils. U.S. Dept. Agr. Handbook, 60.

Taghizadeh-Toosi, A., Clough, T. J., Sherlock, R. R. \& Condron, L. M. (2012). Biochar adsorbed ammonia is bioavailable. Plant and soil, 350(1-2), 57-69.

Sakin, E. \& Yanardag, I.H. (2019). Effect of Applıcation of Sheep Manure and its Bıchar on Carbon Emissions in Salt Affected Calcareous Soil in Sanlıurfa region se Turkey. Fresenius Environmental Bulletin 28(4):2553-2560.

Sönmez, S., Kaplan, M., Sönmez, N. K. \& Kaya, H. (2006). Topraktan Yapılan Bakır Uygulamalarının Toprak $\mathrm{pH}^{\prime}$ sı ve Bitki Besin Maddesi İçerikleri Üzerine Etkisi. Akdeniz Üniversitesi Ziraat Fakültesi Dergisi, 19(1), 151-158.

Steiner, C., Teixeira, W. G., Lehmann, J., Nehls, T., de Macêdo, J. L. V., Blum, W. E. H. \& Zech, W. (2007). Long term effects of manure, charcoal and mineral fertilization on crop production and fertility on a highly weathered central Amazonian upland soil. Plant and Soil. 291, 275-290.

Tiftik, B. E. (2006). Çay Fabrikası Atığının Pirolizi ve Piroliz Ürünlerinin Incelenmesi Yüksek Lisans Tezi, Ankara Üniversitesi, Ankara, Türkiye.

Veiga, T. R. L. A., Lima, J. T., Dessimoni, A. L. D. A., Pego, M. F. F., Soares, J. R. \& Trugilho, P. F. (2017). Different Plant Biomass Characterizations for Biochar Production. Cerne, 23(4), 529-536.

Whalen, J. K. \& Chang, C. (2002). Macroaggregate characteristics fin cultivated soil after 25 annual manure applications. Soil Sci. Soc. Am. J., 66, 16371647.

Yu, X.Y., Ying, G. G. \& Kookana, R. S. (2006). Sorption and desorption behaviors of diuron in soils amended with charcoal. Journal of Agricultural and Food Chemistry, 54: 8545-8550. 